\title{
Impact Analysis of Highway System on Wetland Vegetation in Northern China
}

\author{
Tong YANG ${ }^{\mathrm{a}, 1}$, Cheng $\mathrm{CHEN}^{\mathrm{b}, 2}$, Xiaoke $\mathrm{WANG}^{\mathrm{a}}$ and Shilin $\mathrm{XIE}^{\mathrm{a}}$ \\ ${ }^{a}$ Research Center for Eco-Environmental Sciences, Chinese Academy of Sciences \\ 100085, China \\ b Inner Mongolia Communications Investment Group Co., Ltd, Inner Mongolia 010020, \\ China
}

\begin{abstract}
Wetlands in northern China are complex ecosystems composed of grasslands, lakes, rivers and swamps, which have immense ecological values. When a highway system passes through a wetland, it has adverse effects on its ecosystem. However, in many cases, it is difficult to avoid a highway system pass through a wetland. Taking the Erka wetland in northern China as an example, nine survey lines, perpendicular to the highway, were set up. According to the distance from the highway, the plant multi-element information was collected. After the analysis of plant growth habits, spatial characteristics and profile features, the following four conclusions were drawn: (1) the highway system divided the plants habitat and made the vegetation communities on both sides develop anisotropically; (2) the highway system interfered with the interspecific competition of the nearby plant populations, making it easier for the plant communities with fast propagation speed, drought resistance and anti-interference to establish advantages; (3) the plant growth within $80 \mathrm{~m}$ of the highway was inhibited and (4) the wetland plant community succeeded to grassland plant community. In order to reduce the adverse impact of highway system on wetland ecosystems, it is suggested that in the follow-up highway upgrading project, either diversion of highway or construction of bridge or culvert excavation should be considered.
\end{abstract}

Keywords. Wetland ecosystems, ecological environment, highway system

\section{Introduction}

Wetland is known as the "kidney" of the earth. It has many functions, such as regulating hydrology [1] and climate [2], purifying environment [3] and maintaining biodiversity [4]. A lot of attention has been paid by the society to its ecological value. Erka wetland is located in the west of Hulunbeier grassland, the largest meadow grassland in China, adjacent to Russia in the north, and belongs to the international wetland. Haiman first-class highway passes through Erka wetland, which has a variety of impacts on the ecological environment of this wetland, resulting in destruction of its integrity and change of plant, animal and ecosystem functions. Scientific evaluation and understanding of the objective impact of highway system on the vegetation

${ }^{1}$ Email: yt61051@126.com

2 Corresponding Author, Cheng CHEN, Inner Mongolia Communications Investment Group Co., Ltd, Inner Mongolia 010020, China; ${ }^{*}$ ccimba425@163.com. 
community of Erka wetland is of great significance for wetland environment protection and ecological restoration [5].

Previous studies have shown that the impacts of highway on wetland vegetation mainly include: (1) subgrade and pier permanently occupy the growth space of vegetation and reduce the distribution area of natural vegetation [6]; (2) oil pollution caused by running, dripping and leaking during vehicle operation endangers the growth of vegetation [7]; (3) asphalt pavement sewage discharged to wetland after surface precipitation reduces biodiversity [8]; (4) road dust covers the leaf surface of plants on both sides and reduces photosynthesis [9]; (5) the highway divides the plant community into two parts, which blocks the cross pollination, and then produces island effect [10]; (6) the highway across the wetland improves the accessibility of humans to the wetland, which is convenient for human trampling, picking or destroying the vegetation [11]; (7) the transportation facilities promote the appreciation of the surrounding land value, increase the development and construction projects, and stress the vegetation growth environment [12]; (8) the highway across the wetland makes easy to absorb heat to create highway heat island, change the surrounding microclimate and affect the growth and development of vegetation [13]; and (9) accident vehicles increase the risk of wetland vegetation fire [14].

Based on the study of historical data and remote sensing image interpretation, nine survey lines perpendicular to the highway were set up to collect multi-element information of plants at different distances from the highway. Based on the analysis of plant habits, spatial characteristics and profile features, this paper reveals the response of wetland vegetation to highway system, evaluates the impact of highway construction on ecological environment of the Erka wetland, predicts its change trend, and puts forward suggestions for ecological protection and restoration.

\section{Materials and Methods}

\subsection{Research Area Overview}

Erka wetland is located at the northern border of China, its two thirds belong to China and one third belongs to Russia. Erka wetland is surrounded by Dalan'eromu River, Xinkai River and Hailar River, and formed by the periodic flooding of these three rivers. It belongs to the typical herbaceous swamp complex wetland ecosystem in the southern margin of cold temperate zone. The geographical coordinates are $117^{\circ} 44^{\prime} 50$ $" \sim 117^{\circ} 51^{\prime} 57^{\prime \prime} \mathrm{E}$ and $49^{\circ} 25^{\prime} 17^{\prime \prime} \sim 49^{\circ} 32^{\prime} 28^{\prime \prime} \mathrm{n}$, with a total area of $6679 \mathrm{hm}^{2}$. The annual average temperature is about $-1.0^{\circ} \mathrm{C}$, and the highest temperature is $38^{\circ} \mathrm{C}$. The average annual frost free period is about 100 days, and the annual precipitation is 280-300 mm.

Erka wetland is rich in biodiversity [15]. About 141 species of birds have been identified in the wetland. Among them, 6 species are under first class and 26 species under second class national protection. There are 37 species of fish, 5 species of amphibians, 38 species of mammals and 257 species of vascular plants. Erka wetland has a vast area and a good natural habitat. It has various wetland types including river, lake, swamp etc. It provides habitat for many rare and endangered birds. Together with other wetlands in the region, it constitutes an important channel for migratory birds in East Asia. At the same time, it has important functions of water conservation, flood storage and water purification; irrigation water resources for Manzhouli City, and 
provides 50 million tons of drinking water every year. The remote sensing images (summer 2020) and field photos of Erka wetland are shown in figure 1.

\subsection{Principles and Methods}

In order to find out the influence of Haiman first-class highway on the plants in Erka wetland, nine vertical and evenly distributed survey lines were set up by using the transect survey method and interpretation of remote sensing images, including 5 transects on the south side of the highway and 4 transects on the north side. The length of transect was $1.8 \mathrm{~km}$, and the distance between the transects was about 1 highway. The distance between the transects changed the vegetation from dense to sparse with the distance from the vertical highway. In addition, some intensive sampling points were set up along the highway, and a total of 145 plant quadrats were investigated (figure 2). The sampling method was random sampling, and all the plant species, coverage, richness, height, community type and other related information in the sample box were recorded on the spot.

Firstly, the vegetation survey data were digitized, and the information on plant species, abundance, height and relative frequency was integrated. The relative frequency is the percentage of the number of times a plant is observed in the total number of times, which represents the dominance and breadth of a plant in the evaluation area. Then, based on arcgis10.5 platform, the spatial analysis and mapping were carried out. Vegetation coverage was estimated by kriging method [16], and the plant diversity was interpolated by inverse distance weighting [17] to judge the relationship between the vegetation distribution of Erka wetland and Haiman highway. Finally, data mining and knowledge discovery were carried out on the results of statistical analysis and spatial analysis, and a variety of knowledge including biological characteristics, spatial relationship and object-oriented were sorted out. Combined with the biological characteristics and suitable habitats of different vegetation communities, the spatial change characteristics of Erka wetland vegetation and its relationship with Haiman first-class highway were evaluated.

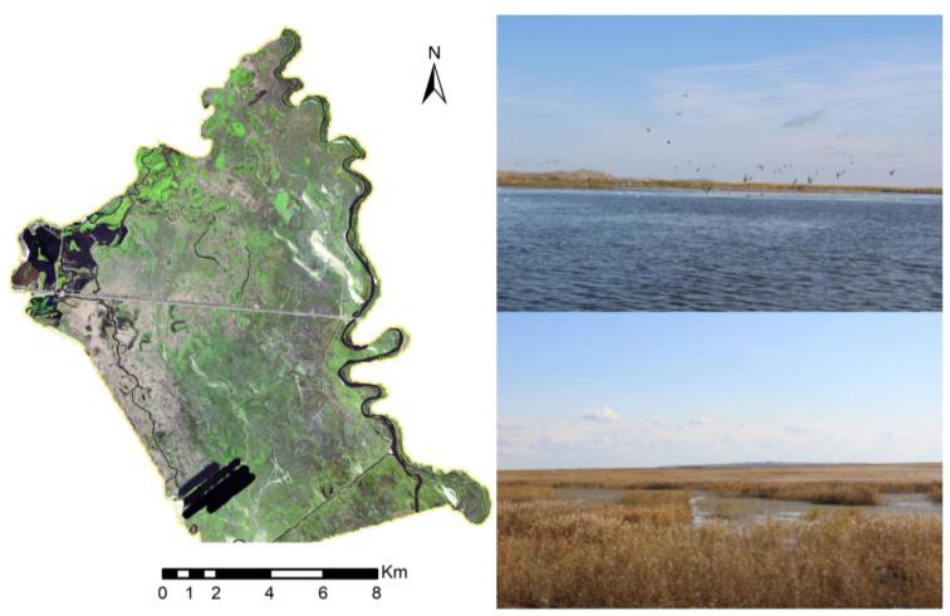

Figure 1. Remote sensing images and local photos of Erka wetland. 


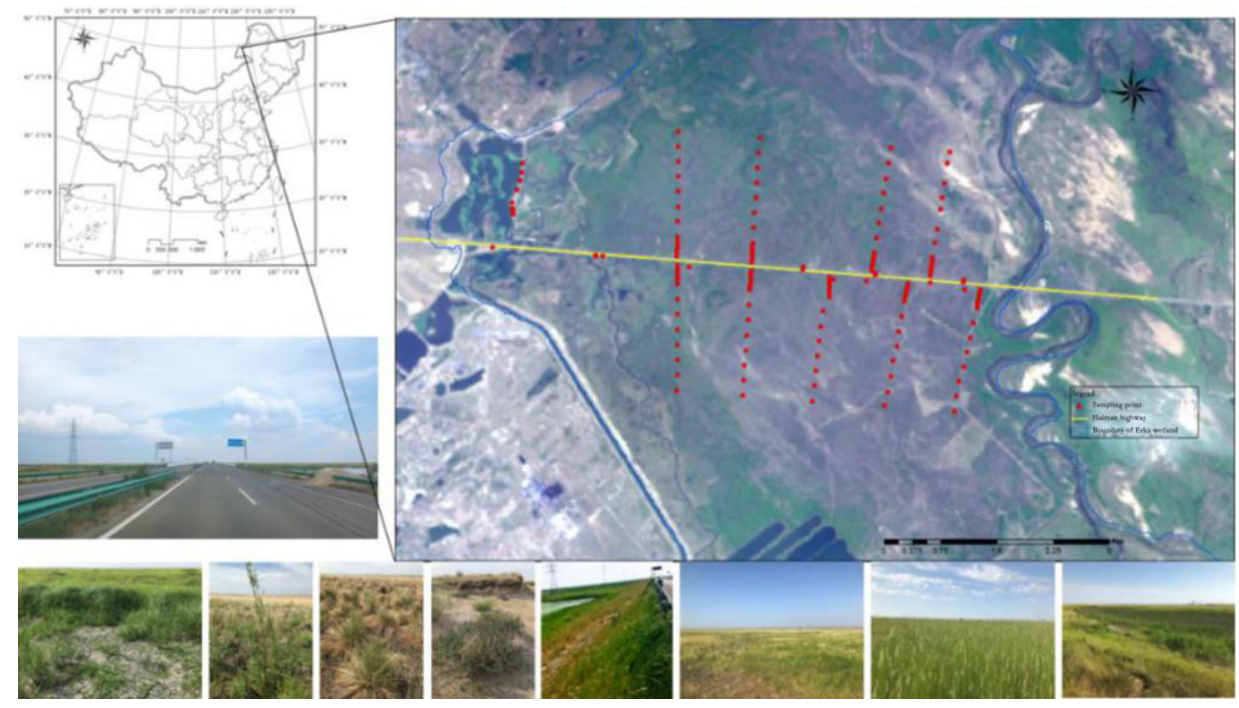

Figure 2. Investigation location map of plant sample plot.

\section{Results}

\subsection{Plant Multi-element Information Sorting}

The flora of Erka wetland is dominated by Pan Arctic, paleoarctic and Eastern Arctic, followed by dauri Mongolia, and some East Asian and European Siberian species [18]. The flora is complex in composition and diverse in vegetation communities. Wetland vegetation includes aquatic vegetation, swamp vegetation and meadow vegetation. Meadow vegetation is the main vegetation type in the Erka wetland. Most of the plants are perennial herbs with strong asexual reproduction ability. Wetland vegetation is rich in species. About 71 species of plants belonging to Rosaceae, Gramineae, Sedaceae, Compositae, Leguminosae, Polygonaceae, Quinoaceae and Ranunculaceae families were found in 9 lines. Most of the vegetation communities belonged to Rosaceae, Gramineae and Sargassaceae families. The statistics of multi-element information of plants collected from 9 transects are shown in table 1 . The relative frequency, average number of plants per plot and average height of each plant were also estimated.

Table 1. Multi factor statistics of plants near roads (COP: many plants in standard plots, SP: moderate, SOL: few, UN: individual).

\begin{tabular}{llll}
\hline Latin names of plants & Frequency (\%) & Quantity & PH (cm) \\
\hline Potentilla anserina L. & 73.10 & COP & 13.4 \\
Potentilla flagellaris Willd. ex Schlecht. & 3.45 & UN & 25.8 \\
Potentilla multicaulis Bge. & 0.69 & UN & 40 \\
Potentilla longifolia Willd. ex Schlecht. & 2.07 & SOL & 35.6 \\
Artemisia mongolica (Fisch. ex Bess.) Nakai & 4.14 & UN & 51.7 \\
Artemisia scoparia Waldst. et Kit. & 8.97 & UN & 21.4 \\
Artemisia rubripes Nakai & 3.45 & UN & 10.3 \\
Artemisia sieversiana Ehrhart ex Willd. & 6.90 & UN & 10
\end{tabular}


Artemisia tanacetifolia Linn.

Carex vesicaria L.

$1.38 \quad$ UN 20

Carex reptabunda (Trautv.) V. Krecz.

28.28

SP $\quad 39$

Carex bohemica

2.07

SOL 22.7

Carex appendiculata

0.69

UN 35

Astragalus adsurgens Pall.

0.69

UN 9

Astragalus adsurgens Pall.

8.97

SOL $\quad 41.2$

Astragalus mongholicus Bunge

0.69

Agrostis gigantea Roth

0.69

Sonchus arvensis L.

6.21

UN

Phragmites communis (Cav.) Trin. ex Steud

UN $\quad 50$

Taraxacum mongolicum Hand. -Mazz.

22.07

SOL $\quad 47.8$

Gramineae hierochloeglabra Trin

11.72

SP $\quad 12.1$

Saussurea amara (L.) DC.

23.45

SP $\quad 46.5$

Calamagrostis epigeios (L.) Roth

12.41

SOL $\quad 10.2$

Leymus chinensis (Trin.) Tzvel.

16.55

Scirpus yagara Ohwi

3.45

Poa subfastigiata Trin.

13.79

Inula japonica Thunb.

4.83

20.69

Calamagrostis pseudophragmites (Haller f.) Koeler

2.76

Phalaris arundinacea L.

21.38

SP $\quad 24.8$

Polygonum lapathifolium L.

20.00

Beckmannia syzigachne.

6.90

SOL $\quad 10.8$

Stachys chinensis Bunge ex Benth.

0.69

Lysimachia vulgaris L. var.davurica (Ledeb.) R. Knuth 0.69

Stellaria palustris

1.38

Sium suave Walt.

10.34

Equisetum arvense L.

0.69

Deyeuxia langsdorffii (Link) Kunth

26.21

Cephalanoplos setosum (Willd.) Kitam.

Cirsium setosum

6.21

Plantago depressa Willd.

Alopecurus aequalis Sobol.

Ixeris denticulata

Puccinellia distans (L.) Parl.

Hordeum brevisubulatum (Trin.) Link

Polygonum hydropiper L.

Cicuta virosa $\mathrm{L}$.

Carex duriuscula C.A.Mey.

0.69

Alopecurus brachystachyus Bieb.

Calamagrostis angustifolia Kom.

0.69

Vicia multicaulis Ledeb.

0.69

Eleocharis dulcis (Burm. f.) Trin.

Rorippa globosa (Turcz.) Hayek

Polygonum persicaria L.

Stellaria media (L.) Cyr.

Juncus gracillimus V. Krecz. et Gontsch.

2.07

Agrostis alba L.

Lagedium sibiricum (L.)Sojak

UN 50

COP $\quad 102.5$

SP $\quad 19.1$

32

UN 40

UN 44

UN 25

SOL $\quad 25.6$

Stachys baicalensis Fisch. ex Benth.

Ranunculus japonicus Thunb.

UN 5

UN 60

UN 20

UN $\quad 30$

UN $\quad 40$

UN $\quad 30$

UN $\quad 37.6$

UN 40

UN 48

UN 50

UN $\quad 31.6$

UN $\quad 42.3$

UN $\quad 30.1$

UN 28.9

UN 15 


\begin{tabular}{llcc} 
Scirpus validus Vahl & 2.07 & $\mathrm{UN}$ & 130 \\
Polygonum L. & 1.38 & $\mathrm{UN}$ & 32 \\
Kochia prostrata (L.) Schrad. & 0.69 & $\mathrm{UN}$ & 30 \\
Salsola collina Pall. & 0.69 & $\mathrm{UN}$ & 10 \\
Chenopodium album L. & 0.69 & $\mathrm{UN}$ & 35 \\
Polygonum amphibium L. & 2.07 & $\mathrm{UN}$ & 25 \\
Melilotus officinalis (L.) Pall. & 2.07 & $\mathrm{UN}$ & 24.3 \\
Triglochin palustre & 0.69 & $\mathrm{UN}$ & 60 \\
Alisma plantago-aquatica Linn. & 1.38 & $\mathrm{UN}$ & 50 \\
Acorus calamus L. & 0.69 & $\mathrm{UN}$ & 100 \\
\hline
\end{tabular}

It can be seen from table 1 that Potentilla anserina L. was the most widely distributed plant in Erka wetland. It was recorded in 106 plots of 145 survey plots. It was the main constructive species or the main associated species. The relative frequency was $73.1 \%$, the average abundance was COP, and the average plant height was $13.4 \mathrm{~cm}$. Potentilla anserina L. is a perennial herb of Rosaceae family. It has a wide ecological range and strong adaptability [19]. It can grow in the low humidity environment at an altitude of 400-4200 m. It can safely overwinter when there is snow and temperature $-34{ }^{\circ} \mathrm{C}$. Through morphological plasticity, it can survive and grow in different plant communities. The green period can reach 200-220 d. It is mainly found in Alpine swamps with weeds. Potentilla anserina L. likes humid environment, and has strong tolerance to waterlogging, cold, salinity and trample, but not drought. It was widely distributed in the flood plain meadow of Erka wetland.

Carex vesicaria L. was widely distributed in the survey area, with relative frequency of $28.28 \%$, average abundance of SP and average plant height of $39 \mathrm{~cm}$. It was mainly distributed in the flood plain meadow on the west bank of Hailaer River and sporadically in other areas of wetland. It was the main associated species and sub-dominant species in the survey area. It is a perennial herb belonging to Cyperaceae family, which is mainly found in river valleys, marshes, waterside, swamp meadows and swamps [20]. Carex vesicaria L. is sensitive to soil moisture. As the water level of Hailaer River passing through Erka wetland drops; plant community on the west bank of Hailaer River withers, green vegetation coverage diminishes, litter accumulates and the ecosystem degenerates rapidly. This phenomenon should be paid due attention.

Deyeuxia langsdorffii Kunth was widely distributed in the survey area, with relative frequency of $26.21 \%$, average abundance of COP and average plant height of $55.8 \mathrm{~cm}$. It was an important constructive and dominant species in the area. Deyeuxia langsdorffii Kunth is a perennial herb of Gramineae family. It is mainly found in hillside grassland, forest and valley wet grassland with an altitude of 700-3600 m. It likes wet and can also grow in dry habitat [21]. The plants are mainly distributed in Tatau area within $200 \mathrm{~m}$ on both sides of Haiman highway, and compete with each other when they are associated with Carex, and the plant height becomes more than 100 $\mathrm{cm}$.

Phalaris arundinacea L. is a perennial herb also belonging to Gramineae family. It is mainly found in flood plain meadow and lakeside area with low temperature and abundant water. It is tolerant to waterlogging, drought and cold, but not to soil salinity. Its relative frequency in the area was $21.4 \%$ with an average plant height of $102.5 \mathrm{~cm}$. It had strong reproductive capacity and formed strong clumps in the survey area, with plant height up to $170 \mathrm{~cm}$. Its transverse stem can squeeze the growth space of other plants and form a single dominant species community. It was an important group building and dominant species in the area. Phalaris arundinacea L. is a C3 plant with 
high photosynthetic efficiency, which plays a protective role in the stability of grassland ecosystem. It was mainly distributed in the naturally conserved area on the north side of Haiman highway.

Hierochloe glabra Trin. is a perennial herb of Gramineae family. It can reproduce asexually and sexually. The relative frequency was $23.5 \%$, the average abundance was SP, and the average plant height was $24.8 \mathrm{~cm}$. The rhizome of Hierochloe glabraTrin. is fleshy, brittle and perishable. It can survive for 2-3 years in soil. Its photosynthetic rate may be inhibited due to interspecific competition of plants and therefore the plant height is low. Hierochloe glabra Trin. mostly appears as an associated species in a stable ecosystem. However, in the investigation area, several quadrats on both sides of Haiman highway were covered bythis species, which indicated that the ecosystem near the highway was extremely unstable, and it could quickly establish through its short-term spatial expansion ability.

Inula japonica Thunb. is a perennial herb of Compositae family. It is common on roadside hills, wet grassland, river banks and strips of hills and mountains at an altitude of $150-2400 \mathrm{~m}$. In the investigation area, the relative frequency was $20.7 \%$, the average abundance was SP, and the average plant height was $18.6 \mathrm{~cm}$. In some areas close to the north of Haiman highway, Inula japonica Thunb. appeared as a dominant species, while in other areas, it was mostly an associated species. In addition, it is resistant to saline and alkali soils and pollution, and is not affected by road pollutants, so it can breed in large numbers near the road and become an important roadside species.

Phragmites communis Trin. ex Steud(reed) is a representative plant of wetland ecosystem, which can absorb phosphorus from water and plays an important role in purifying sewage [22]. Large area of reed can regulate the climate, conserve water, provide forage, and serve as habitat and breeding home for birds. According to historical records, the reed output of Erka wetland was 6,000 t/a. Unfortunately, reeds were only found near the Russian border in this survey, and sporadically distributed in other areas. It indicated that the hydrological environment of Erka wetland had been degraded and reeds gradually gave way to weeds which are relatively drought tolerant in interspecific competition. The wetland ecosystem was changing into a flood plain meadow ecosystem, and the wetland area was rapidly drying. Therefore, comprehensive protection measures were urgently needed.

The above mentioned seven species were the dominant species with relative frequency more than $20 \%$ in the study area, and the others with relative frequency less than $20 \%$ and average abundance of SOL or UN were not typical. Other plants with relatively high observation frequency and abundance were Polygonum lapathifolium L., Sonchus arvensis L., Calamagrostis epigeios (L.) Roth., Scirpus yagara Ohwi and Saussurea amara (L.) DC. The dominant plant communities in Erka wetland indicated that the regional ecological environment was degenerating and the wetland ecosystem was evolving into grassland ecosystem. Especially in the vicinity of highway, weed plant community had established advantages, squeezing the living space of native plant community. In the west bank of Hailaer River, a large area under Carex vesicaria L. community had withered, indicating that soil moisture was depleting.

\subsection{Plant Spatial Characteristics}

All the plant survey information was correlated with the point coordinates, and the spatial interpolation calculation was carried out on the platform of Arcgis10.5, in which the vegetation coverage was calculated by kriging interpolation algorithm. Plant 
diversity is characterized by plant richness, that is, the number of plant species per unit area. Inverse distance weighting was used to obtain the macro plant distribution information of Erka wetland in July 2020, as shown in figure 3.

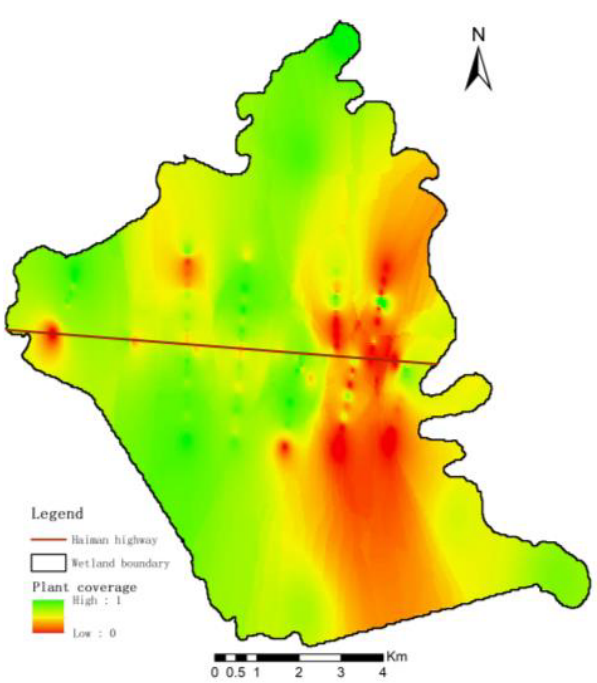

(a) Plant coverage

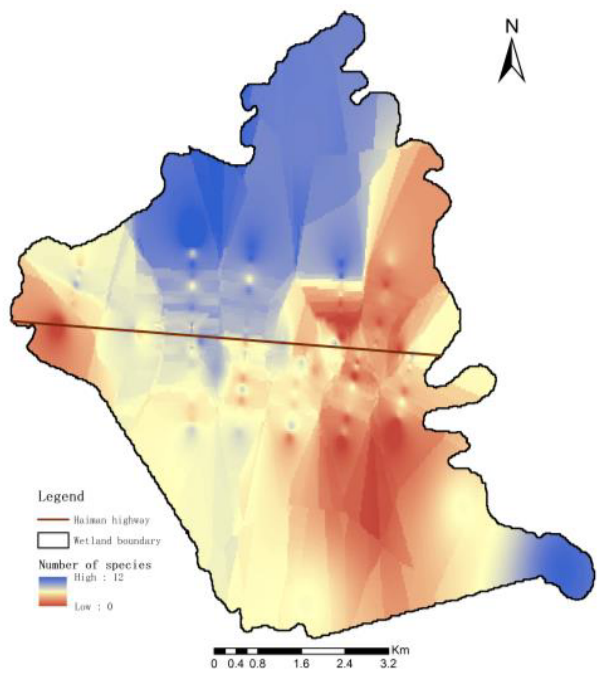

(b) Plant diversity

Figure 3. Spatial characteristics of wetland vegetation.

It can be seen from figure 3a that the vegetation coverage of Erka wetland was obviously different and there was a certain difference between the north and south of the highway. In the past 45 years, the climate change in this area showed a trend of warming and drying. The annual evapotranspiration increased significantly, which was not conducive to the water conservation of Erka wetland. At the same time, the rivers flowing through the Erka wetland and Hulun Lake were in a huff and puff relationship. Under the condition of giving priority to the ecological water supply of Hulun Lake, the runoff of Hailaer River flowing through the east of Erka wetland was decreased, the soil moisture of the surrounding flood plain meadow tended to be arid, and a large number of Carex vesicaria L. communities with poor drought resistance were withered in batches and did not return to green in July. In addition, Haiman highway destroyed the integrity and connectivity of wetland ecosystem, and some river beds and ditches dried up, which further worsened the ecological environment of the study area. Vegetation coverage was directly affected by the highway, especially on both sides of the road, which decreased with the increase of vertical distance. The vegetation coverage near the highway was generally low, and the vegetation coverage within 100 $\mathrm{m}$ on both sides of the highway was significantly lower than the background value. The highway caused pollution hazards and water shortage, which were not conducive to vegetation growth.

Compared with vegetation coverage, plant diversity was more sensitive to the disturbance of highway system. It can be seen from figure $3 \mathrm{~b}$ that the spatial differentiation of plant diversity in Erka wetland was very significant and consistent with the distribution of vegetation coverage. It showed that the east of Erka wetland 
and the west bank of Hailaer River turned to bare soil with low biodiversity and low vegetation coverage, and the ecological service function declined sharply. With increasing distance from the highway, the plant diversity showed a gradient change. Within $800 \mathrm{~m}$ of the north side of the middle section of Haiman highway, the plant species increased with the increase of the distance away from the highway. However, there was no significant difference in the south side of the middle section of the highway. In the east and west sections of the highway, the plant diversity was low and the difference was not obvious. The above characteristics showed that the wetland ecosystem with good ecological environment and rich plant diversity was highly vulnerable due to the disturbance of highway system.

\subsection{Plant Profile Features}

The information of dominant plants in the evaluation area was sorted to explore the changing trend of coverage and average plant height of different plant species with road distance. The top 12 dominant species were Potentilla anserina L., Carex vicaria L., Deyeuxia langsdorffii Kunth, Phalaris arundinacea L., Hierochloeglabra Trin., Inula japonica Thunb., Phragmites communis Trin. ex Steud, Polygonum lapathifolium L., Sonchus arvensis L., Calamagrostis epigeios(L.) Roth., Scirpus yagara Ohwi and Saussurea amara(L.) DC. The relationship between growth information of different plants and road distance is shown in figure 4.

It can be seen from figure 4 that with the increase of vertical distance from Haiman highway, average plant height of five plant species showed an increasing trend. Except for Sonchus arvensis L., the plants were tall with greater biomass, which grew poorly near the road due to the inhibition of soil nutrients, reduction in soil moisture and presence of road salinity. They grew better far away from the highway due to the improvement of soil nutrients and soil moisture. The average plant height of six species did not change significantly. Only the average height of Deyeuxia langsdorffii Kunth decreased with the increase of distance from the highway. With the increase of soil moisture content due to distance from the road, Deyeuxia langsdorffii Kunth gradually gave way toPhalaris arundinacea L. with greater plant height in interspecific competition. With the increase of road distance, plant coverage of only Phalaris arundinacea L. and Hierochloeglabra Trin. increased significantly, while the coverage of other 10 species decreased or remained unchanged. In terms of plant richness, the average richness of 3 plant species increased with the distance from the highway, while for the other 9 species it decreased or remained unchanged.

The variation trend of average coverage, average height and species richness of all plants at different road distances are shown in figure 5. Within the range of 10-80 m from the middle line of the road, the species richness, total coverage and average height of plant communities were on the rise; within the range of $80-1800 \mathrm{~m}$ from the middle line of the road, the plant profile features were different with the local ecological environment. Therefore, the disturbance range of highway to vegetation was within 80 $\mathrm{m}$ of highway. After $80 \mathrm{~m}$, the influence of highway system on vegetation decreased rapidly and then disappeared. 

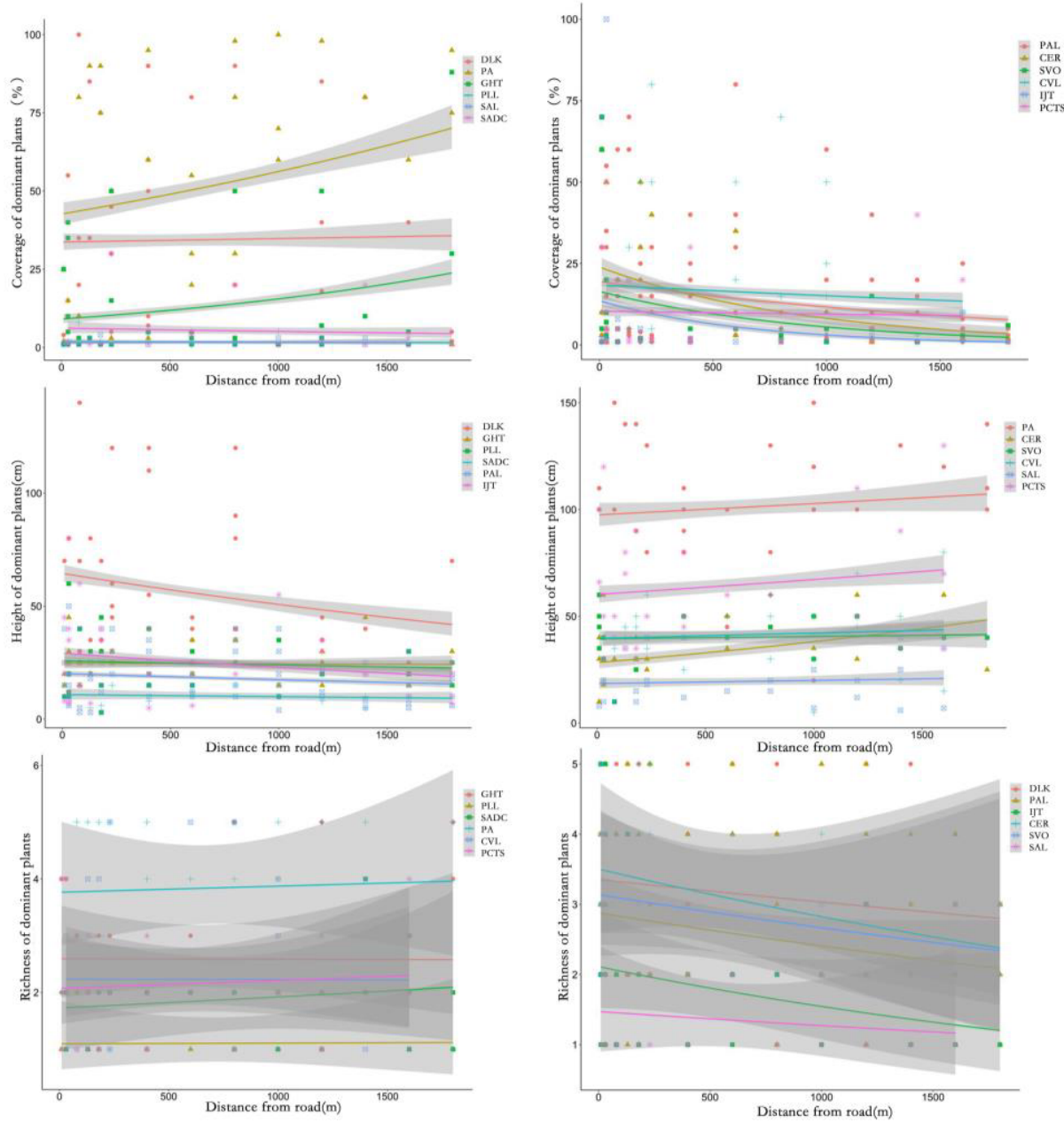

Figure 4. Relationship between growth information of different plants and highway distance (unit: height $\mathrm{cm}$; coverage $\%$, richness: $1=\mathrm{UN}, 2=\mathrm{SOL}, 3=\mathrm{SP}, 4=\mathrm{COP}, 5=\mathrm{SOC})$.

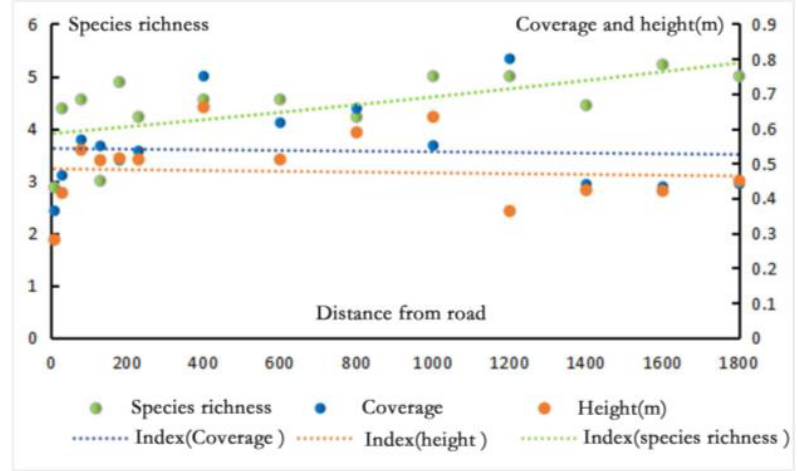

Figure 5. Response of vegetation to highway distance. 


\section{Discussion}

Haiman first-class highway is one of the important highways in China constructed in 2005. It passes through the centre of Erka wetland dividing it into two parts. In order to meet the present increasing traffic demand, the highway will be transformed into expressway. How the new expressway passes through the Erka wetland has once again aroused great concern from all walks of life. Highway system is like the blood arteries of a country, maintaining healthy development of society and economy. The planning and design of highway system is usually based on the principle of minimizing time and maximizing profit. For example, many important transportation routes in Europe today were built on the site of the Roman Avenue 2000 years ago. Nowadays, the concept of environmental protection is being integrated into modern highway construction and a series of measures are adopted to reduce stress on the ecological environment near the highway. However, there are only few options for the protection of wetlands from adverse effects of highways and expressways including highway bypass, bridge construction and culvert excavation.

Among these options, the most thorough scheme for wetland ecosystem protection is highway bypass. However, its construction cost is high. According to the calculations of transportation department, if the new expressway bypasses Erka wetland, it will increase the cost by 5 billion yuan. Considering the economic and social costs, the most likely highway reconstruction scheme is to add culverts. Adding culverts can improve the connectivity of wetlands and improve the local hydrological environment, but it cannot solve the problems of highway sewage, highway heat island, human entry, alien species invasion etc. It is suggested to build protective fence in this section of Expressway to avoid tourists entering, use more environmentally friendly subgrade materials to reduce waste water pollution and take noise reduction measures to avoid frightening the wetland birds.

\section{Conclusions}

In this paper, the vegetation of Haiman highway near Erka wetland section was investigated and the response of plants to the highway system was evaluated by sorting the information of plant multi-elements. The results showed that the influence of the highway system on the nearby vegetation was mainly as follows: blocking the spread and pollination of plants, destroying the local hydrological environment, causing highway pollution, disturbing the interspecific competition among different kinds of plants etc. The scope of influence was 80 mon both sides of the middle line of the highway. The ecological environment of Erka wetland was tending to degenerate and the wetland ecosystem was changing into grassland ecosystem. It is suggested that effective measures should be taken to reduce the negative impact on the wetland system in the follow-up highway reconstruction project.

\section{Acknowledgements}

This work was supported by Ecological impact assessment project of Haiman first-class highway on Erka wetland. We would like to thank the following institutions 
for providing support and helping in wetland survey: Hulunbeier Municipal Government, Hulunbeier Natural Resources Bureau, Hulunbuir Forestry and Grass Bureau, Hulun Lake administration and Hulunbuir Transportation Bureau.

\section{References}

[1] Mansell R S, Bloom S A and Ge S 2000 A model for wetland hydrology: Description and validation Soil Science 165 (5) 384-397.

[2] Fan Y and Miguez-Macho G 2011 A simple hydrologic framework for simulating wetlands in climate and earth system models Climate Dynamics 37 (1-2) 253-278.

[3] Daugherty E E, Mckee G A, Bergstrom R and Burton S 2019 Hydrogeomorphic controls on soil carbon composition in two classes of subalpine wetlands Biogeochemistry 145 (1-2) 161-175.

[4] Ward M P, Benson T J, Semel B and Herkert J 2010 The use of social cues in habitat selection by wetland birds Condor 112 (2) 245-251.

[5] Adam E, Mutanga O and Rugege D 2010 Multispectral and hyperspectral remote sensing for identification and mapping of wetland vegetation: a review Wetlands Ecology and Management 18 (3) 281-296.

[6] Li L, Guan W, Li G, Wang L and Feng Y 2008 Research on impacts of western expressway construction on swamp resource sand protective measures Technology of Highway and Transport (05) 143-145.

[7] Chen Y C, Yang Z M and Juan H E 2011 Matching study on treatment of sewage from highway service area by ecological soil system in Chongqing Environmental Science 32 (4) 1066-1072.

[8] Liu X, Li K, Chen X, Lu S, Chen F and Li J 2015 Purification of stormwater runoff by ecological planting tank Chinese Journal of Environmental Engineering 9 (006) 2681-2686.

[9] Bao L, Qu L, Ma K and Lin L 2016 Effects of road dust on the growth characteristics of Sophora japonica L. seedlings Journal of Environmental Sciences 8 (46) 147-155.

[10] Mcleese R L and Whiteside E P 1977 Ecological effects of highway construction upon Michigan woodlots and wetlands: Soil relationships Journal of Environmental Quality 6 (4) 467-471.

[11] Kennish and Michael J 2002 Environmental threats and environmental future of estuaries Environmental Conservation 29 (01) 78-107.

[12] Maltby E 2008 Wetland drainage, restoration, and repair Environmental Conservation 35 (1) 91.

[13] Yang Y, Yang J, Zhao T, Huang X and Zhao P 2016 Ecological restoration of highway slope by covering with straw-mat and seeding with grass-legume mixture Ecological Engineering 90 68-76.

[14] Yin S, Shu L, Zhang D, Shan Y, Shuai D, Tang S, Zhang X and Zhang Z 2018 Study on the data characteristics of forest fire sources in Jilin Province Scientia Silvae Sinicae 54 (07) 165-172.

[15] Xie S, Wang X, Yang T, Huang B, Wang W, Lu F, Zhang L, Han B and Ouyang Z 2021 Effect of highways on breeding birds: Example of Hulunbeier, China Global Ecology and Conservation 26 (5) e01554.

[16] Beers W and Kleijnen J 2003 Kriging for interpolation in random simulation Journal of the Operational Research Society 54 255-262.

[17] Gao Z, Xueyi Y E, Zhou T and Song Q 2015 Visualization algorithm of underwater acoustic data based on inverse distance weight interpolation Computer Engineering 41 (9) 266-275.

[18] Yan J, Qi W, Lu J and Ruan H 2015 Flora of wild seed plants in wetlands in Hulunbuir City Wetland Science 13 (001) 66-73.

[19] Yu F, Chen Y and Ming D 2001 Clonal integration enhances survival and performance of Potentilla anserina, suffering from partial sand burial on Ordos Plateau, China Springer Netherlands 15 (4) 303-318.

[20] Odland A 2002 Patterns in the secondary succession of a Carex vesicaria L. wetland following a permanent drawdown Aquatic Botany 74 (3) 233-244.

[21] Wilcox J C, Healy M T and Zedler J B 2007 Restoring native vegetation to an urban wet meadow dominated by reed canarygrass (Phalaris arundinacea L.) in Wisconsin Natural Areas Journal 27 (4) 354-365.

[22] Mcgechan M B, Moir S E Castle K and Smit I 2005 Modelling oxygen transport in a reedbed-constructed wetland purification system for dilute effluents Biosystems Engineering 91 (2) 191-200. 